\title{
Trigger Point Inactivation by Infrared Low Level Laser Therapy Compared With Dry Needling
}

\author{
João Paulo C Tanganeli* and Wanessa C de Souza Zaroni \\ Institution- Cruzeiro do Sul University, Brazil
}

Submission: July 27, 2017; Published: December 01, 2017

*Corresponding author: João Paulo C Tanganeli, Universidade Cruzeiro do Sul- R Galvão Bueno 868, Liberdade, São Paulo Brazil, ZIP Code- 01506 000, Tel: 55(11) 3862-6880; Email: tanganeliodonto@hotmail.com

\begin{abstract}
The scientific literature is replete with evidence about the benefits of using low intensity laser therapy in pain control. It's anti-inflammatory, analgesic and tissue recovery have been extensively discussed and tested. Regarding the inactivation of trigger points present in the orofacial muscles, also there are already some studies demonstrating this performance. However, to date, we could not find experiments that made the comparison between other techniques and laser therapy in the same patient, with at least two active trigger points. This paper will present a patient case report, with two characteristic trigger points (TP), one in each masseter and visual analog pain scale with the same intensity. Dry needling was performed in one TP and infrared laser therapy at the other side.
\end{abstract}

Results: after the use of the protocol proposed, a significant reduction in pain on both sides occurred. The patient reported satisfaction with the results, noting that with laser therapy there was no discomfort, both in the application act as postoperative, present in the dry needling.

Conclusion: according to our experiment and the current literature, both dry needling as infrared low intensity laser therapy were an effective way to inactivate the trigger points; the use of laser maybe considered superior, from the standpoint of patient comfort.

Keywords: Trigger points; Dry needling; Laser therapy; Masticatory muscle

\section{Introduction}

The myofascial pain syndrome is one of the most common pathology present in the daily pain clinic, including orofacial pain. It has being described as a sensory, motor and autonomic symptoms caused by trigger points [1]. Myofascial pain syndrome is a welldocumented and an area of great interest. In physiological terms, an active myofascial trigger point (TP) expresses a disruption in biochemical activity of the muscle [2]. An active trigger point always causes a pain complaint. Always tender, it is recognized by the patient by its compression. The TP produces a local and referred pain, among other symptoms [1]. It prevents a full lengthening of the muscle, weakens and mediates a local twitch response of the muscle fibers, when adequately stimulated. When compressed within the patient's pain tolerance, may produce a referred motor and autonomic phenomenon, generally in its pain reference zone [1]. In general, authors agree that a muscle overuse or direct trauma leads to the development of trigger points. Sustained and repetitive low-level muscle contraction, eccentric muscle contraction and maximal or submaximal concentric muscle contraction are pointed as a trigger point cause.1During muscle contraction, oxygen and glucose are necessary, but they are in short supply. Multiple techniques have been tested, like ischemic compression, dry needling, laser, ultrasound, lidocaine injections, etc. Good results have been obtained and the therapy choice depends on the professional experience and patient agreement [3-7]. Many manuscripts maybe be found in the current literature, involving the laser therapy and dry needling for the trigger point inactivation $[3,8,9]$ but most of them comparing these techniques in different patients. Our proposal is to compare dry needling and laser therapy in the same patient, in two TP, eliminating the bias of pain behavior, that maybe present when comparing different people.

\section{Literature Review}

Myofascial pain syndrome is described as the sensory, motor and autonomic symptons caused by trigger points [1] There is a general agreement that muscle overuse or trauma to the muscle can lead to the trigger points occurrence $[1,3,9]$. 
Different techniques have been researched for the inactivation of trigger points. Manual therapy with ischemic compression [10], ultrasound [5], dry needling [6,9], laser [4] has been described as effective. The comparison of laser therapy and dry needling is present in the literature $[3,8]$, but these studies compared the two techniques in different persons. Ilbudu et al. [3] evaluated laser therapy for TPs treatment in comparison with dry needling and placebo, concluding that laser is useful as a treatment modality in myofascial pain syndrome. In a study including 243 patients, Simunovic4 states that laser therapy may be used as monotherapy or associated with other procedure for the trigger point management. Recently, Uemoto et al. [8] presents a review, concluding that laser therapy is indicated as the method of choice for patients with fear of needles, but further controlled studies are still needed.

\section{Case Report}

MMS 37 years, female. Pain complaint in both sides of the face. On palpation exam, we noted the presence of hypersensitive nodes on the right and left masseter, with local and referred pain. The right masseter nodule caused pain referred to the eyebrow, while the left caused pain in the region of upper molars, characterizing the presence of trigger points. The pain on both sides was present at least for one year and no treatment was instituted before. After a detailed explanation of the problem to the patient, the treatment proposed was dry needling to the right and laser therapy to the left side. The patient signed the consent form about the experiment, being informed in detail about the proposal and its possible consequences.

\section{Dry needling protocol}

Acupuncture needles, gauge $0,20 \times 0,13 \mathrm{~mm}$, trade mark Moxon, manufactured by Brasil 3B Scientific, sterile and disposable were utilized. Before the procedure, the skin surface was disinfected with alcohol. Then we marked the exact spot with pen, applied ice and then started the handling of the needle. After this manipulation, we applied ice again and instructed the patient to ice application at home, replacing a warm compress after 24 hours. The procedure was repeated 2 times a week, during 2 weeks (4 sessions).

\section{Laser therapy protocol}

After the exact point identification, infrared low-level laser, trade mark Duo Laser manufactured by MM Optics, Brazil was applied to the trigger point. The lases parameters were: $810 \mathrm{~nm}$ of wavelength, with the laser light emitting semiconductor GaA1As and InGaAlP, $4 \mathrm{~J} / \mathrm{cm} 2$, for 20sec, 100mW, 2 times a week, during 2 weeks.

\section{Results}

In the initial evaluation, using a Visual Analog Scale for pain, when 0 means no pain and 10 the maximal pain, the patient reported intensity 9 for both TPs. After the first week, the patient related a significant improvement, with the reduction of the pain intensity to 4 at the dry needling side and 3 for the laser side. After the second week, both sides were evaluated by the patient as only 1 in the scale. We evaluate the patient 4 weeks after completion of the proposed treatment and she reported that the reduction in pain intensity had remained, giving back her quality of life.

\section{Discussion}

Since the publication of Trigger Points Manual, its features and patterns, by the authors Travell \& Simons [11], myofascial pain syndrome has been the subject of study in the area of pain. The mechanisms proposed to explain the etiology and pathophysiology of the occurrence of this phenomenon, although well studied and elucidated in many aspects, are still not completely understood $[1,2]$. Thus, the proposed treatments are varied and it is possible to differentiate which techniques have sufficient scientific evidence to their application, and which should be discarded [3$9,10]$. Since we can already say that conservative therapies have great results, we must seek among the existing techniques, which are less potential for side effects, especially post-operative. It is also important to meet the needs and expectations of patients.

According to the IASP (www.iasp.org), laser therapy has highly evidence for treatment of myofascial pain syndrome. The dry needling has been widely used for this purpose, but many patients complain of trans and postoperatively symptoms, in addition to the many cases of needle phobia [8]. The study design used in some publications, in our opinion, can induce errors of assessment, since the subjectivity and individual behavioral characteristics are different. In example, the study realized by Ilbudu et al. 3 divided the patients in three groups: 1 - stretching exercises and placebo laser; 2- stretching and dry needling; 3 - stretching and laser. None of the patients received laser therapy and dry needling. Uemoto et al. [8] claim that the literature reports greater efficacy with the use of laser over dry needling. It has been suggested that improvements in the microcirculation through the administration of laser may be due to the better oxygen supply to the cells under conditions of hypoxia and help remove the waste products of cell metabolism, thereby breaking the vicious cycle of pain, muscle spasm and further pain, but the studies hasn't compared the twos techniques in the same patient. Thus, it is important to note that in our study the two techniques were applied in the same patient, thus seeking to eliminate possible change of outcome resulting from psychological factors, such as pain behavior, different from one individual to another. In conclusion, once it is established that we can get good results with both therapies, the use of the laser has to be advantageous, since it is practically zero the occurrence of side effects and the fact that its application is totally painless.

\section{References}

1. Bron C, Dommerholt JD (2012) Etiology of myofascial trigger points. Curr Pain Headache Rep 16(5): 439-444.

2. Moraska AF, Hickner RC, Kohrt WM, Brewer A (2013) Changes in body flow and cellular metabolism at a myofascial trigger point release. Arch Phys Med Rehabil 94(1): 196-200. 
3. Ilbuldu E, Cakmak A, Disci R, Aydin R (2004) Comparison of laser, dry needling and placebo laser treatments in myofascial pain syndrome. Photomed Laser Surg 22(4): 306-311.

4. Simunovic Z (1996) Low level laser therapy with trigger points technique: a clinical study on 243 patients. J Clin Laser Med Surg 14(4) 163-167.

5. Manca A, Limonta E, Pilurzi G, Ginatempo F, De Natale ER, et al. (2014) Ultrasound and laser as stand-alone therapies for myofascial trigger points: a randomized, double-blind, placebo-controlled study. Physiother Res Int 19(3): 166-175.

6. Gonzalez-Perez LM, Infante-Cossio P, Granados-Nuñez M, UrrestiLopez FJ (2012) Treatment of temporomandibular myofascial pain with deep dry needling. Med Oral Patol Oral Cir Bucal 17(5): 781-785.

7. Dommerholt J, Layton M, Hooks T, Grieve R (2015) A critical overview of the current myofascial pain literature. J Bodyw Mov Ther 19(4): 736-746.

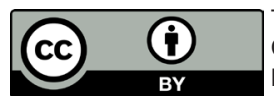

This work is licensed under Creative Commons Attribution 4.0 Licens

DOI: 10.19080/ADOH.2017.06.555688
8. Uemoto L, Nascimento de Azevedo R, Almeida Alfaya T, Nunes Jardim Reis R, Depes de Gouvêa CV, et al. (2013) Myofascial trigger point therapy: laser therapy and dry needling. Curr Pain Headache Rep 17(9): 357.

9. Kietrys DM, Palombaro KM, Azzaretto E, Hubler R, Schaller B (2013) Effectiveness of dry needling for upper-quarter myofascial pain: a systematic review and meta-analysis 43(9): 620-634.

10. Rayegani SM, Bayat M, Bahrami MH, Raeissadat SA, Kargozar E (2014) Comparison of dry needling and physiotherapy in the treatment of myofascial pain syndrome. Clin Rheumatol 33(6): 859-864.

11. Travell J, Simons DG (1983) Myofascial pain and dysfunction: the trigger point manual. Baltimore: Williams and Wilkins.

\section{Your next submission with Juniper Publishers} will reach you the below assets

- Quality Editorial service

- Swift Peer Review

- Reprints availability

- E-prints Service

- Manuscript Podcast for convenient understanding

- Global attainment for your research

- Manuscript accessibility in different formats

(Pdf, E-pub, Full Text, Audio)

- Unceasing customer service

Track the below URL for one-step submission https://juniperpublishers.com/online-submission.php 